УДК 539.3

DOI https://doi.org/10.26661/2413-6549-2021-1-05

\title{
ЧИСТИЙ ЗГИН СМУГИ (БАЛКИ) ІЗ ДВОМА СПІВВІСНИМИ ТРІЩИНАМИ, ПЕРПЕНДИКУЛЯРНИМИ ДО ЇЇ ОСІ, ОДНА 3 ЯКИХ ЗНАХОДИТЬСЯ В ЗОНІ СТИСКАЛЬНИХ НАПРУЖЕНЬ
}

\author{
Опанасович В. К. \\ доктор фізико-математичних наук, професор, \\ професор кафедри механіки \\ Львівський національний університет імені Івана Франка \\ вул. Університетська, 1, Львів, 79000, Україна \\ orcid.org/0000-0002-7248-4505 \\ opanasovuch.viktor@gmail.com \\ Слободян М. С. \\ кандидат фізико-математичних наук, дочент, \\ доиент кафедри механіки \\ Львівський національний університет імені Івана Франка \\ вул. Університетська, 1, Львів, 79000, Украӥна \\ orcid.org/0000-0001-5357-8584 \\ slobkolia@gmail.com
}

Білаш О. В.

кандидат економічних наук, доцент,

дочент кафедри інженерної механіки

Національна академія сухопутних військ імені гетьмана Петра Сагайдачного

вул. Героїв Майдану, 32, Львів, 79012, Украӥна

orcid.org/0000-0001-7515-7641

oksana.bilash@gmail.com

\begin{abstract}
Ключові слова: чистий згин, смуга (балка), тріщина, гладкий контакт берегів тріщини, комплексні потенціали, задачі лінійного спряження, коефіиієнти інтенсивності напружень, критичне навантаження.
\end{abstract}

У роботі досліджена задача про чистий згин зосередженою смуги (балки) 3 двома співвісними наскрізними тріщинами різної довжини, береги яких вільні від зовнішнього навантаження. Тріщини перпендикулярні до осі балки, причому одна 3 тріщин частково знаходиться в зоні стискальних напружень, так що іiї береги частково гладко контактують, тобто в області контакту берегів тріщини має місце рівність контактних напружень та відповідних компонент переміщень, а дотичні напруження рівні нулю. Друга тріщина перебуває в зоні розтягувальних напружень. Використовуючи методи теорії функцій комплексної змінної та комплексні потенціали двовимірної теорії пружності, розв'язок задачі зведено до задач лінійного спряження, отримано явний вигляд для комплексних потенціалів та коефіцієнтів інтенсивності напружень. Записано рівняння для знаходження параметра, за допомогою якого визначають довжину області контакту берегів тріщини. На основі енергетичного критерію руйнування знайдено критичне значення згинального моменту, при якому смуга (балка) зруйнується. Проведено числовий аналіз задачі, з якого випливає, що при наближенні неконтактуючої тріщини до контактуючої область контакту останньої зменшується, а при іії віддаленні наближається до області контакту для одинокої контактуючої тріщини, одна вершина якої знаходиться в зоні стискальних напружень балки, а інша - в зоні 
розтягувальних напружень. Зауважимо, що руйнування балки може відбуватися як з вершини контактуючої тріщини, яка знаходиться в зоні розтягувальних напружень балки, так і з вершини неконтактуючої тріщини залежно від іiі положення і розмірів. При цьому повністю контактуюча тріщина не впливає на напруженодеформований стан балки.

\title{
PURE BENDING OF STRIP (BEAM) WITH TWO COAXIAL CRACKS PERPENDICULAR TO ITS AXIS AND ONE OF THEM IS LOCATED IN ZONE OF COMPRESSIVE STRESSES
}

\author{
Opanasovych V. K. \\ Doctor in Physics and Mathematics, Professor, \\ Professor at the Department of Mechanics \\ Ivan Franko National Univercity of Lviv \\ Universytetska str., 1, Lviv, 79000, Ukraine \\ orcid.org/0000-0002-7248-4505 \\ opanasovuch.viktor@gmail.com \\ Slobodyan M. S. \\ Ph.D. in Physics and Mathematics, Associate Professor, \\ Associate Proffessor at the Department of Mechanics \\ Ivan Franko National Univercity of Lviv \\ Universytetska str., 1, Lviv, 79000, Ukraine \\ orcid.org/0000-0001-5357-8584 \\ slobkolia@gmail.com \\ Bilash O. V. \\ Ph.D. in Economic Sciences, Associate Professor, \\ Associate Professor at the Department of Engineering Mechanics \\ Hetman Petro Sahaidachnyi National Army Academy \\ Heroiv Maydana str., 32, Lviv, 79000, Ukraine \\ orcid.org/0000-0001-7515-7641 \\ oksana.bilash@gmail.com
}

Key words: pure bending, strip (beam), crack, smoothly contact of crack faces, complex potentials, linear conjunction problem, stress intensity factor, critical load.
The problem of pure bending of concentrated strip (beam) with two coaxial through cracks that have different length and their faces are free from external load is solved in the article. Cracks are perpendicular to beam axis, moreover one of them is partly located in zone of compressive stresses and its faces partly smoothly contact, scilicet in contact zone of crack faces is equaling of contact stress and relevant displacement component and tangent stress is equal zero. The second crack is located in the zone of tensile stresses. Using methods of function of a complex variable theory and complex potentials of two-dimentional stresses theory, solution of the problem is reduced to the linear conjunction problem. Explicit view for complex potentials and stress intensity factors is received. Equation for finding parameter by which determine length of contact zone of crack faces is written. Based on energy fraction criteria the critical value of bending moment at which strip (beam) will destroyed is found

Numerical analysis of the problem is done. From this analysis follows that: if non-contact crack is approaches to the contact crack the contact zone of the last is decreases; if non-contact crack is distances from the contact crack then its approaches to contact zone for lonesome contact crack. One top of this 
lonesome contact crack is located in zone of compressive stresses of the beam and the second top is located in zone of tensile stresses.

Notice, that destruction of the beam can occur both from the top of contact crack, which is located in zone of tensile stress and from the top of non-contact crack depending on its position and size. At the same time, completely contact crack does not effect on the tensely strained condition of the beam.

Вступ. Балочні елементи конструкцій широко використовуються в інженерній практиці. Вони можуть містити тріщини, які є сильним концентратором напружень, що значно зменшує надійність і міцність такого конструктивного елемента.

Під дією зовнішнього навантаження береги тріщин можуть контактувати. Дослідженням плоских контактних задач теорії тріщин в однорідних тілах займалось багато дослідників, вони розвинули методи розв'язування такого типу задач, що відображено у працях Масаковського В.І., Загубіженка П.А. [1], Гриліцького Н.Д., Кіта Г.С. [2], Гриліцького Д.В., Лущишина Р.М. [3], Панасюка В.В., Лозового Б.А. [4; 5], Саврука М.П. [6], Фильштинського Л.А., Хвороста В.Ф. [7], Guz A. N., Zozulya V.V. [8]. У науковій літературі $\epsilon$ велика кількість критеріїв руйнування тіл із тріщинами [10-12].

У працях [4; 5] досліджені задачі згину смуги (балки) з тріщиною перпендикулярної до іiі осі. Розглянуто випадок тріщини симетрично розміщеної відносно іiі осі, береги якої контактують, так і випадок тріщини розміщеної в зоні розтягуючи напружень. Використовуючи методи теорій функцій комплексної змінної та комплексні потенціали, розв'язок задачі зведено до задач лінійного спряження та сингулярного інтегрального рівняння відносно невідомих контактних напружень, визначено комплексні потенціали, довжину області контакту, граничне навантаження, коли тріщина почне поширюватися.

У даній роботі досліджена подібна задача, про чистий згин смуги (балки), коли в ній наявні дві співвісні тріщини нерівної довжини, які перпендикулярні до іiї осі, причому береги однісї з тріщин приходять у гладкий контакт по деякій iii частині, а інша тріщина перебуває в зоні розтягуючих напружень. Використовуючи методи теорії функцій комплексної змінної та комплексні потенціали, розв'язок задачі зведено до задач лінійного спряження, знайдено явні вирази для комплексних потенціалів, записано рівняння для знаходження дожини області контакту берегів тріщини, визначено коефіцієнти інтенсивності напружень, а на основі енергетичного критерію руйнування $[11 ; 12]$ знайдено критичне значення моменту, при якому балка почне руйнуватися.

Формулювання задачі. Дослідимо напружено-деформований стан ізотропної смуги (балки), 3 прямолінійними наскрізними співвісними тріщинами, завдовжки $2 l_{j}(j=1,2)$ перпендикулярними до іiі осі. Береги тріщини вільні від зовнішнього навантаження, а балка перебуває в умовах чистого згину зі згинальним моментом $M$. Нехай $2 h-$ висота поперечного перерізу смуги, а $2 \tilde{b}$ - його ширина. Вважаємо, що береги однієї з тріщин під дією зовнішнього навантаження прийшли в гладкий контакт по деякій частині, а інша тріщина перебуває в зоні розтягуючи напружень. Введемо декартову систему координат $O x y$, у серединній площині смуги, направивши вісь $O y$ по осі балки, а вісь $O x$ вздовж лінії, де розміщені тріщини. Позначимо вершини тріщини через $\mathrm{A}_{\mathrm{j}}(j=1,4)$, яким відповідають координати $\left(a_{j}, 0\right)$ (див. рис. 1), при цьому координати кінця області контакту берегів тріщини будуть $(\lambda, 0)$. Відрізок дійсної осі, де береги тріщини контактують позначимо через $L$, а де береги тріщин не контактують - через $L_{1}$. Абсциси центрів тріщин позначимо через $\mathrm{x}_{\mathrm{j}}(j=1,2)$.

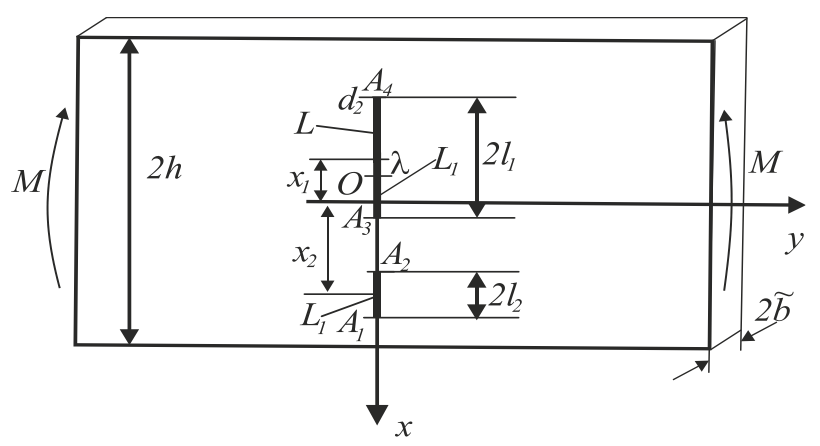

\section{Рис. 1. Схема навантаження балки та розміщення тріщин}

Згідно формулювання задачі маємо такі крайові умови

$$
\begin{gathered}
\sigma_{y y}^{ \pm}=0, \quad \sigma_{x y}^{ \pm}=0, \quad x \in L_{1} ; \quad \sigma_{y y}^{+}=\sigma_{y y}^{-}, \\
v^{+}-v^{-}=0, \quad \sigma_{x y}^{ \pm}=0, \quad x \in L ;
\end{gathered}
$$

де $\sigma_{y y}$ i $\sigma_{x y}-$ компоненти тензора напружень; значками $+\mathrm{i}-$ позначено граничне значення відповідної величини при $y \rightarrow \pm 0, v-$ компонента вектора переміщення точки балки на вісь $O y$.

Побудова розв'язку задачі. Введемо комплексні потенціали $\Phi(z)$ і $\Omega(z)$ [9] та скористаємося залежностями

$$
\begin{array}{r}
\sigma_{y y}-i \sigma_{x y}=\Phi(z)+\Omega(\bar{z})+(z-\bar{z}) \overline{\Phi^{\prime}(z)}, \\
2 \mu \partial_{x}(u+i v)=\kappa \Phi(z)-\Omega(\bar{z})-(z-\bar{z}) \overline{\Phi^{\prime}(z)},
\end{array}
$$

де $\mu$ - модуль зсуву; $\kappa$ - стала Мусхелішвілі; $\partial_{x} f=\partial f / \partial x ; \quad u-$ компонента вектора переміщення точки балки на осі $O x, z=x+i y, i^{2}=-1$. 
Згідно [6] функції $\Phi(z)$ і $\Omega(z)$ за великих $|z|$ можна подати у вигляді

$$
\Phi(z)=C z / 4+O\left(\frac{1}{z^{2}}\right), \Omega(z)=3 C z / 4+O\left(\frac{1}{z^{2}}\right),
$$

де $C=M / I, I-$ момент інерції попереченого перерізу балки відносно його нейтральної лінії, $I=4 \tilde{b} h^{3} / 3$.

Із крайової умови

$$
\left(\sigma_{y y}-i \sigma_{x y}\right)^{+}-\left(\sigma_{y y}-i \sigma_{x y}\right)^{-}=0, x \in L+L_{1} .
$$

з урахуванням (2) отримаємо

$$
(\Phi(x)-\Omega(x))^{+}-(\Phi(x)-\Omega(x))^{-}=0, \quad x \in L+L_{1} \text {. }
$$

Врахувавши (4) та розв'язавши задачу лінійного спряження (5), одержимо

$$
\Phi(z)-\Omega(z)=-\frac{C}{2} z .
$$

Із крайової умови

$$
\sigma_{x y}^{+}+\sigma_{x y}^{-}=0, x \in L+L_{1},
$$

врахувавши (2) i (6), одержимо

$$
(\Phi(x)+\bar{\Phi}(x))^{+}+(\Phi(x)+\bar{\Phi}(x))^{-}=0, \quad x \in L+L_{1} .
$$

Якщо розв'язати задачу лінійного спряження (7) та врахувати (4), то матимемо

Із крайових умов

$$
\Phi(z)-\bar{\Phi}(z)=0 .
$$

$$
\begin{gathered}
v^{+}-v^{-}=0, \quad x \in L, \\
\sigma_{y y}^{+}+\sigma_{y y}^{-}=0, \quad x \in L_{1},
\end{gathered}
$$

беручи до уваги (3), (2) та (6), отримаємо

$$
\begin{aligned}
& {[\Phi(x)+\bar{\Phi}(x)]^{+}-[\Phi(x)+\bar{\Phi}(x)]^{-}=0, x \in L,} \\
& {[\Phi(x)+\bar{\Phi}(x)]^{+}+[\Phi(x)+\bar{\Phi}(x)]^{-}=0, x \in L_{1} .}
\end{aligned}
$$

Розв'язавши задачу лінійного спряження (9), матимемо

$$
\Phi(z)+\bar{\Phi}(z)=-\frac{C z}{2}+2 X(z) \mathrm{P}(z) .
$$

де

$$
\begin{gathered}
X(z)=\sqrt{\frac{z-\lambda}{\left(z-a_{1}\right)\left(z-a_{2}\right)\left(z-a_{3}\right)},} \\
\mathrm{P}(z)=C_{0}+C_{1} z+C_{2} z^{2},
\end{gathered}
$$

$C_{j}(j=\overline{0,2})$ - невідомі сталі.

Додаючи (8) i (10), одержимо

$$
\Phi(z)=-\frac{C z}{4}+X(z) \mathrm{P}(z) .
$$

Зауважимо, коли $\lambda=a_{3}$, тобто перша тріщина повністю приходить у гладкий контакт, то в цьому випадку

$$
X(z)=\frac{1}{\sqrt{\left(z-a_{1}\right)\left(z-a_{2}\right)}},
$$

то як видно з (13), (6), (2), (3) повністю контактуюча тріщина не впливає на напружено-деформований стан смуги (балки).

Виберемо вітку функції $X(z)$ таку, яка при великих $|z|$ має розвинення

$$
X(z)=\frac{1}{z}+\frac{\rho_{1}}{z^{2}}+\frac{\rho_{2}}{z^{3}}+\ldots,
$$

$$
\text { де } \begin{aligned}
\rho_{1} & =\frac{1}{2}\left(\sum_{i=1}^{3} a_{i}-\lambda\right), \rho_{2}=\frac{1}{8}\left\{3\left(a_{1}^{2}+a_{2}^{2}\right)+2 a_{1} a_{2}+\right. \\
& \left.+\left(a_{3}-\lambda\right)\left[2\left(a_{1}+a_{2}\right)+3 a_{3}+\lambda\right]\right\} .
\end{aligned}
$$

Розвиваючи праву і ліву частину залежності (13) в ряди при великих $|z|$ та враховуючи (4), (12), (14), (15), отримаємо

$$
\begin{gathered}
c_{2}=\frac{C}{2}, \quad c_{1}=-\frac{C}{4}\left(\sum_{i=1}^{3} a_{i}-\lambda\right), \\
c_{0}=\frac{C}{16}\left\{\left(a_{3}-\lambda\right)\left[2\left(a_{1}+a_{2}\right)-a_{3}-3 \lambda\right]-\left(a_{1}-a_{2}\right)^{2}\right\} .
\end{gathered}
$$

Знайдемо параметр $\lambda$, за допомогою якого можна знайти довжину контактуючої частини тріщини.

Врахувавши залежність (3), можемо записати

$$
\begin{gathered}
2 \mu \partial_{x}\left[(u+i v)^{+}-(u+i v)^{-}\right]= \\
=\kappa\left[\Phi^{+}(x)-\Phi^{-}(x)\right]+\Omega^{+}(x)-\Omega^{-}(x), x \in L .
\end{gathered}
$$

Якщо прийняти до уваги (6), то з (17) отримаємо

$$
\begin{gathered}
2 \mu \partial_{x}\left(v^{+}-v^{-}\right)=(\kappa+1) \operatorname{Im}\left[\Phi^{+}(x)-\Phi^{-}(x)\right], \\
x \in L .
\end{gathered}
$$

Так як

$$
\int_{a_{3}}^{\lambda} \partial_{x}\left(v^{+}-v^{-}\right) d x=0
$$

то врахувавши (13) і (18), з (19) одержимо рівняння для знаходження параметра $\lambda$, тобто довжини зони контакту берегів тріщини

$$
\int_{a_{3}}^{\lambda} \mathrm{P}(x) \sqrt{\frac{x-\lambda}{\left(a_{1}-x\right)\left(a_{2}-x\right)\left(a_{3}-x\right)}} d x=0 .
$$

В (20) зробимо заміну

$$
x=a u+b,
$$

в результаті отримаємо

$$
\int_{-1}^{1} \tilde{\mathrm{P}}(u) \sqrt{\frac{1-u}{(1+u)(c-u)(d-u)}} d u=0
$$

де

$$
\begin{gathered}
a=\frac{\lambda-a_{3}}{2}, b=\frac{\lambda+a_{3}}{2}, c=\frac{a_{2}-b}{a}, d=\frac{a_{1}-b}{a}, \\
\tilde{\mathrm{P}}(u)=\mathrm{P}(a u+b) .
\end{gathered}
$$

Інтеграл, що входить у (21) будемо вираховувати числово [6], в результаті матимемо 


$$
\sum_{m=1}^{M} \sin ^{2} \frac{g m-1}{4 M} \pi \tilde{\mathrm{P}}\left(t_{m}\right) \frac{1}{\sqrt{\left(c-t_{m}\right)\left(d-t_{m}\right)}}=0
$$

де

$$
t_{m}=\cos \frac{2 m-1}{2 M} \pi, \quad m=\overline{1, M} .
$$

Коефіцієнти інтенсивності напружень знайдемо за формулами [6]

$$
\begin{aligned}
& K_{1 j}-i K_{2 j}=2 \lim _{x \rightarrow a_{j}+0}\left[\sqrt{2\left(x-a_{j}\right)} \Phi(x)\right], j=1,3, \\
& K_{12}-i K_{22}=2 \lim _{x \rightarrow a_{2}-0}\left[\sqrt{2\left(a_{2}-x\right)} \Phi(x)\right] .
\end{aligned}
$$

Якщо врахувати (13), то для визначення коефіцієнтів інтенсивності напружень (23) отримаємо наступні формули

$$
\begin{aligned}
& K_{11}=2 \sqrt{2} \sqrt{\frac{a_{1}-\lambda}{\left(a_{1}-a_{2}\right)\left(a_{1}-a_{3}\right)}} \mathrm{P}\left(a_{1}\right), \\
& K_{12}=-2 \sqrt{2} \sqrt{\frac{a_{2}-\lambda}{\left(a_{1}-a_{2}\right)\left(a_{2}-a_{3}\right)}} \mathrm{P}\left(a_{2}\right), \\
& K_{13}=-2 \sqrt{2} \sqrt{\frac{a_{3}-\lambda}{\left(a_{1}-a_{3}\right)\left(a_{2}-a_{3}\right)}} \mathrm{P}\left(a_{3}\right), K_{2 j}=0, j=\overline{1,3} .
\end{aligned}
$$

Для визначення критичного значення моменту $M$, коли смуга (балка) зруйнується, скористаємося енергетичним критерієм руйнування [11; 12]

$$
\gamma^{*}=\frac{\pi}{8 b^{2} E}\left(K_{1}^{2}+K_{2}^{2}\right)
$$

де $E$-модуль Юнга, $\gamma^{*}$ - густина ефективної поверхневої енергії.

Якщо ввести позначення

$$
K_{1 j}=2 \sqrt{2} \frac{M l_{1}}{I} K_{1 j}^{*},
$$

то для визначення критичного моменту будемо таку залежність

$$
M^{*}=\frac{M l_{1}}{\tilde{b}^{2} h^{3} \sqrt{E \gamma^{*}}}=\frac{4}{3 \sqrt{\pi}} \frac{1}{K_{1 j}^{*}},(j=\overline{1,3}),
$$

де

$$
\begin{gathered}
K_{11}^{*}=\sqrt{\frac{\tilde{a}_{1}-\tilde{\lambda}}{\left(\tilde{a}_{1}-\tilde{a}_{2}\right)\left(\tilde{a}_{1}-\tilde{a}_{3}\right)}} \mathrm{P}_{0}\left(\tilde{a}_{1}\right), \\
K_{12}^{*}=-\sqrt{\frac{\tilde{a}_{2}-\tilde{\lambda}}{\left(\tilde{a}_{1}-\tilde{a}_{2}\right)\left(\tilde{a}_{2}-\tilde{a}_{3}\right)}} \mathrm{P}_{0}\left(\tilde{a}_{2}\right), \\
K_{13}^{*}=-\sqrt{\frac{\tilde{a}_{3}-\tilde{\lambda}}{\left(\tilde{a}_{1}-\tilde{a}_{3}\right)\left(\tilde{a}_{2}-\tilde{a}_{3}\right)}} \mathrm{P}_{0}\left(\tilde{a}_{3}\right), \\
\tilde{a}_{i}=a_{i} / l_{1}, \tilde{l}_{2}=l_{2} / l_{1}, \tilde{x}_{i}=x_{i} / l, \quad \tilde{a}_{1}=\tilde{x}_{2}+\tilde{l}_{2}, \\
\tilde{a}_{2}=\tilde{x}_{2}-\tilde{l}_{2}, \quad \tilde{a}_{3}=\tilde{x}_{1}+1, \quad \tilde{a}_{4}=\tilde{x}_{1}-1, \\
\mathrm{P}_{0}(x)=\tilde{c}_{2} x^{2}+\tilde{c}_{1} x+c_{0}, \quad \tilde{c}_{2}=\frac{1}{2}, \quad \tilde{c}_{1}=-\frac{1}{4}\left(\sum_{i=1}^{3} \tilde{a}_{i}-\tilde{\lambda}\right),
\end{gathered}
$$

$$
\tilde{c}_{0}=\frac{1}{16}\left\{\left(\tilde{a}_{3}-\tilde{\lambda}\right)\left[2\left(\tilde{a}_{1}+\tilde{a}_{2}\right)-\tilde{a}_{3}-3 \tilde{\lambda}\right]-\left(\tilde{a}_{1}-\tilde{a}_{2}\right)^{2}\right\} .
$$

Так як $a_{3}<a_{2}$, то має виконуватись нерівність $\tilde{x}_{2}-\tilde{l}_{2}>\tilde{x}_{1}+1$.

Числовий аналіз та висновки. Був проведений числовий аналіз задачі, який поданий на рис. 2 - рис. 4.

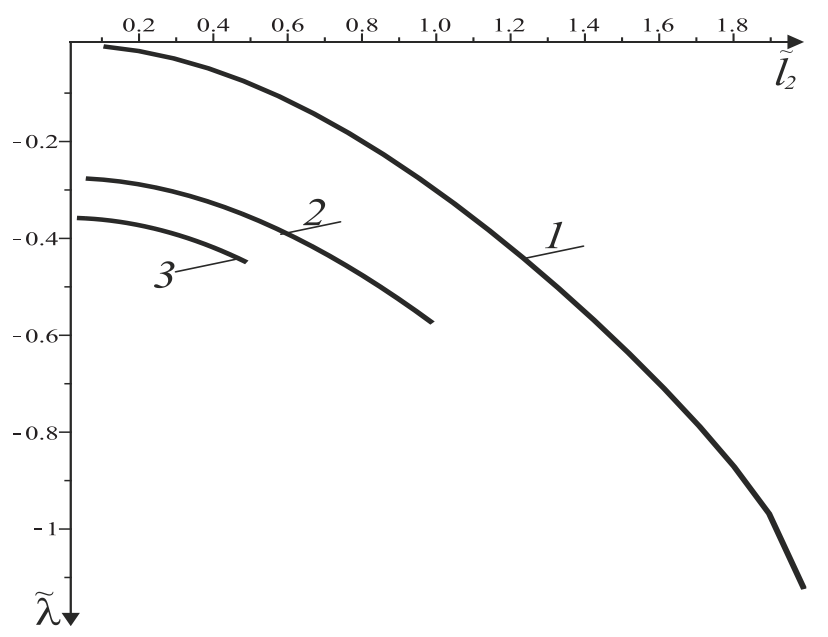

Рис. 2. Графічна залежність параметра $\tilde{\lambda}$ від приведеної довжини неконтактуючої тріщини при різному положенні центру контактуючої тріщини

На рис. 2 дається графічна залежність параметра $\tilde{\lambda}=\lambda / l_{1}$ від зведеної довжини другої тріщини, коли $\tilde{x}_{2}=x_{2} / l=2$, при різному положенні центру першої тріщини $\tilde{x}_{1}=x_{1} / l$. Крива 1 відповідає випадку, коли перша тріщина знаходиться в зоні стискальних напружень $\tilde{x}_{1}=-1$. Крива 2, коли центр першої тріщини знаходиться на осі балки $\tilde{x}_{1}=0$. Крива 3, коли $\tilde{x}_{1}=0,1$. Як видно 3 цього рисунку, при зростанні відносної довжини другої тріщини $\tilde{l}_{2}=l_{2} / l$, довжина зони гладкого контакту першої тріщини зменшується, а коли $\tilde{l}_{2} \rightarrow 0$, то $\tilde{\lambda} \rightarrow-\frac{1}{3}\left(\tilde{x}_{1}+1\right)$, тобто до довжини контакту однакової тріщини.

На рисунку 3 дається графічна залежність критичного моменту $M^{*}$ від відносної довжини другої тріщини $\tilde{l}_{2}$, при різному положенні центру $\tilde{x}_{1}$ першої тріщини, коли $\tilde{x}_{2}=2$. Крива 1 відповідає найбільш віддаленій від осі балки вершини другої тріщини (дальньої) $A_{1}$, крива 2 - середній вершині цієї тріщини $A_{2}$, крива 3 - неконтактуючій вершині першої тріщини $A_{3}$. Рисунки 3a), 3б), 3в) відповідають випадку, коли приведений центр першої тріщини $\tilde{x}_{1}$ знаходиться відповідно на віддалі $\tilde{x}_{1}=-1, \tilde{x}_{1}=0, \tilde{x}_{1}=0,1$. Як видно з рисунка $3 a)$, коли перша тріщина знаходиться в зоні стискальних напружень $\left(\tilde{x}_{1}=-1\right)$ руйнування балки 


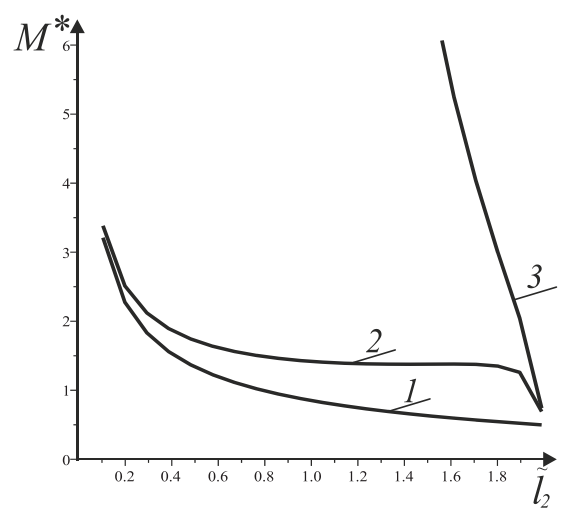

a)

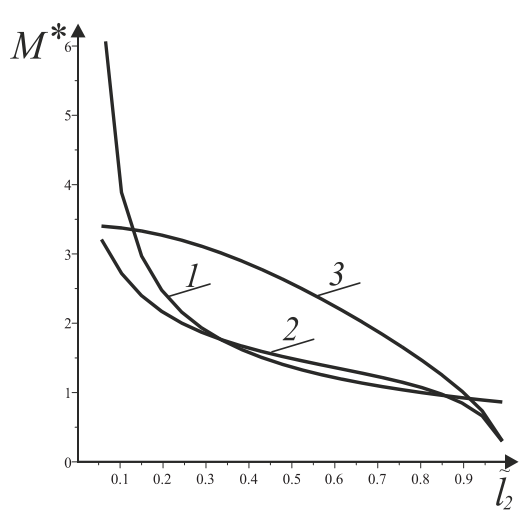

б)

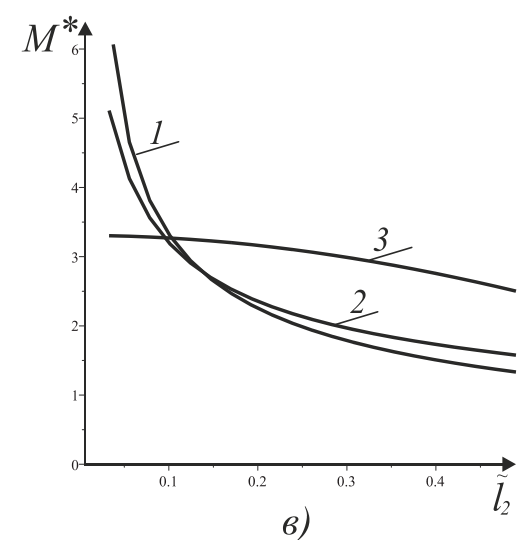

в)

Рис. 3. Графічна залежність критичного моменту $M^{*}$ від приведеної довжини неконтактуючої тріщини при різному положенні центру контактуючої тріщини

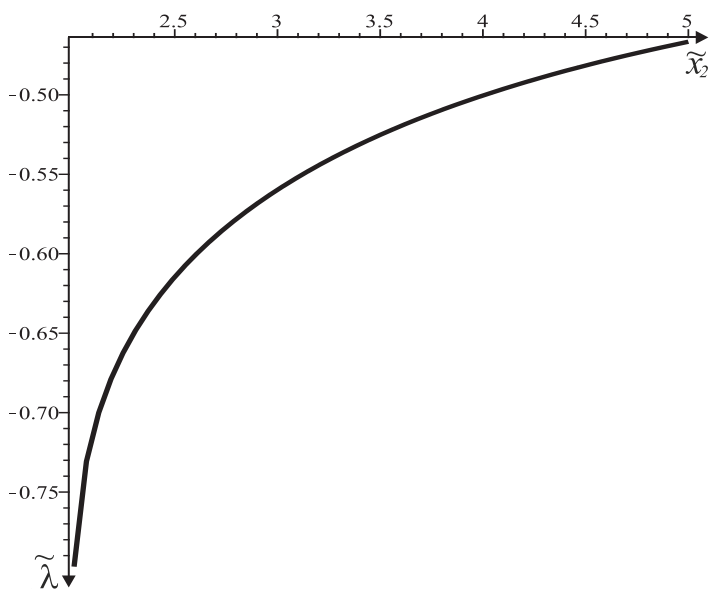

a)

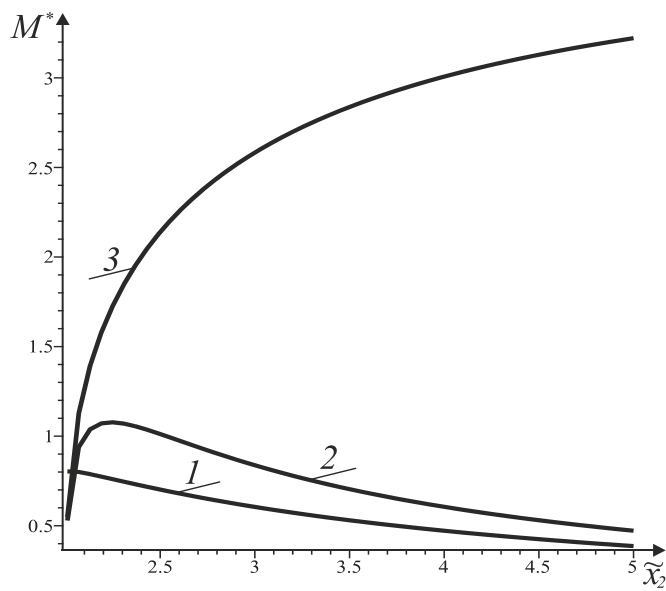

б)

Рис. 4. Графічна залежність параметра $\tilde{\lambda}$ (рис. а)) та критичного моменту $M^{*}$ від положення центру неконтактуючої тріщини (рис. б))

(смуги) буде проходити 3 дальньої вершини першої тріщини незалежно від іії приведеної довжини. Якщо центр першої тріщини знаходиться на осі балки, що відповідає рис. 3б), то руйнування буде проходити з вершин другої тріщини. При малих значеннях $\tilde{l}_{2}$ руйнування відбувається 3 середньої вершини другої тріщини, при подальшому зростанні $\tilde{l}_{2}$ з дальньої вершини цієї тріщини, а потім знову з її середньої вершини тріщини. При віддаленні центру першої тріщини від осі балки, що відображена на рис. 3в), при цьому $\tilde{x}_{1}=0,1$, то при зростанні $\tilde{l}_{2}$ від нуля, руйнування відбувається 3 неконтактуючої вершини першої тріщини, а при подальшому зростанні $\tilde{l}_{2}$ з середньої вершини другої тріщини, а потім з її дальньої вершини.

Для випадку, коли центр першої тріщини знаходиться на осі балки, а довжини першої і другої тріщини однакові, на рисунку 4а) дається графічна залежність параметру $\tilde{\lambda}$, а на рис. 4б) критичного моменту $M^{*}$ від приведеного положення центру другої тріщини $\tilde{x}_{2}$. Позначення кривих на рис. 4б) такі ж, як на рис. 3. Як видно з рис. 4a) при віддаленні центру другої тріщини від першої тріщини довжина зони області її контакту зростає, а при великих $\tilde{x}_{2}$ отримаємо результати для однієї ізольованої тріщини. На рис. 4б) дається графічна залежність зведеного критичного моменту $M^{*}$ від параметра $\tilde{x}_{2}$. Як видно із цього рисунку, коли приведений центр другої тріщини наближається до 2 , то руйнування балки починається 3 середньої вершини другої тріщини, а при зростанні $\tilde{x}_{2}-3$ дальньої вершини цієї тріщини, при цьому величина критичного моменту $M^{*}$ зменшується при зростанні $\tilde{x}_{2}$. 


\section{ЛIТЕРАТУРА}

1. Моссаковский В.И., Загубиженко П.А. Об одной смешанной задаче теории упругости для плоскости, ослабленной прямолинейной щелью. Докл. АН СССР. 1954. 94, № 4. С. 409-412.

2. Грилицкий Н.Д., Кит Г.С. О напряженном состоянии в окрестности трещины с частично контактирующими берегами. Мат. методы и физ.-мех. поля. 1978. № 8. С. 35-39.

3. Гриліцький Д.В., Луцишин Р.М. Напруження в пластинах з коловою лінією розмежування граничних умов. Львів: Вищ. шк., 1975. 116 с.

4. Лозовий Б.Л., Панасюк В.В. Некоторые задачи изгиб полосы с прямолинейной трещиной. Изв. $A H$ СССР. ОТН. 1962. № 1. С. 138-143.

5. Панасюк В.В. Вибрані праці (1954-1970). НАН України. Фіз.-мех. інститут ім. Г.В. Карпенка. Львів, $2001.450 \mathrm{c}$.

6. Саврук М.П. Двумерные задачи упругости для тел с трещинами. К.: Наук. думка, 1981. 324 с.

7. Фильштинский Л.А., Хворост В.Ф. Температурные напряжения в остывающем теле, ослабленном трещиной, с учетом контакта ее берегов. Физ.-хим. механика материалов. 1985. 21, № 3. С. 85-88.

8. Guz A.N., Zozulya V.V. Elastodynamic unilateral contact problems with friction for bodies with cracks. Int. Appl. Mech. 2002. 8, No. 8. P. 895-932.

9. Мусхелишвили Н. И. Некоторые основные задачи математической теории упругости. Москва: Наука, 1966. 707 с.

10. Божидарник В.В., Сулим Г.Т. Елементи теорії пластичності та міцності. Т.2. Львів: Світ, 1999. 420 с.

11. Hui C.Y., Zehnder A.T. A theory for the pasture of thin plates subjected to bending and twisting moments. International Journal of fracture. 1993. Vol. 61. P. 211-229.

12. Zehnder A.T., Viz M.J. Fracture mechanics of thin plates shells under combined membrane, bending and twisting loads. Applied Mechanics Reviews. 2005. Vol. 58. P. 37-48.

\section{REFERENCES}

1. Mossakovskyy V.I., Zahubizhenko P.A. (1954) Ob odnoy smeshanoy zadache teoriyi uprugosti dlya ploskosti, oslablennoy pryamolineynoy shchely [About one mixed problem of the theory of elasticity for a plane weakened by a rectilinear slit]. Dokl. Academy of Sciences of the USSR. 94, No. 4. pp. 409-412. (in Ukrainian)

2. Hrylickyy N.D., Kit H.S. (1978) O napryajennom sostojanii v okresnosti treshchny s chastichno kontaktiruyushchymy beregamy [About the stress state in the vicinity of the crack with partially contacting faces]. Matematichni metodi ta fiziko-mehanichni polia. No. 8. pp. 35-39. (in Ukrainian)

3. Hrylickyy N.D., Lucshyn R.M. (1975) Naprujennya v plastynah z kolovoyu liniyeyu rozmejuvannya granychnyh umov [Tension in plates with a line of stakes between border minds]. Lviv: Vyshcha shkola. (in Ukrainian)

4. Lozovyy B.L., Panasyuk V.V. (1962) Nekotoruye zadachi izgib polosy s pryamolineynoy treshchinoy [Some problems of strip bending with straight crack]. Ed. Academy of Sciences of the USSR. OTN. No. 1. pp. 138-143. (in Ukrainian)

5. Panasyuk V.V. (2001) Vybrani praci [Selected works] (1954-1970). NAS of Ukraine. Phys.-mech. institute named after H.V. Karpenka. Lviv. (in Ukrainian)

6. Savruk M.P. (1981) Dvumernyye zadachi uprugosti dlya tel s treshchenami [Two-dimensional elasticity problems for bodies with cracks]. Kyyiv: Naukova dumka. (in Ukrainian)

7. Filshtinskyy L.A., Hworost V.F. (1985) Temperaturnyye napryajeniya v ostyvayushchem tele, oslablennoy tressshchenoy, s uchotom kontacta yeye beregov [Temperature stresses in a cooling body, weakened by a crack, taking into account the contact of its banks]. Phys.-Chem. mechanics of materials. 21, No. 3. pp. 85-88. (in Ukrainian)

8. Guz A.N., Zozulya V.V. (2002) Elastodynamic unilateral contact problems with friction for bodies with cracks. Int. Appl. Mech. 8, No. 8. P. 895-932.

9. Mushelishvili N.I. (1966) Nekotoryye osnovnyye zadachi matematicheskoy teorii uprugosti [Some basic problems of the mathematical theory of elasticity]. Moscow: Nauka. (in $\mathrm{Ru}$ )

10. Bozhydarnyk V.V., Sulym H.T. (1999) Елементи теорії пластичності та міцності [Elements of plasticity and strength theory]. Lviv: Svit. (in Ukrainian)

11. Hui C.Y., Zehnder A.T. (1993) A theory for the pasture of thin plates subjected to bending and twisting moments. International Journal of fracture. Vol. 61. pp. 211-229.

12. Zehnder A.T., Viz M.J. (2005) Fracture mechanics of thin plates shells under combined membrane, bending and twisting loads. Applied Mechanics Reviews. Vol. 58. pp. 37-48. 